\title{
VARIABILIDADE PLUVIOMÉTRICA NA MICRORREGIÃO DE ITAPORANGA, NO ESTADO DA PARAÍBA
}

\author{
NASCIMENTO, Maxsuel Bezerra do - maxsuel10gba@hotmail.com \\ Universidade Estadual da Paraíba / UEPB
}

SILVA, Linaldo Freire - linaldo.fs@hotmail.com Universidade Federal da Paraíba / UFPB

MEDEIROS, José Ludemário da Silva - joseludemariomedeiros@gmail.com Universidade Estadual da Paraíba / UEPB

ARAÚJO, Lincoln Eloi de - lincolneloi@yahoo.com.br Universidade Federal da Paraíba / UFPB

SANTOS, Laércio Leal dos - laercioeng@yahoo.com.br Universidade Estadual da Paraíba / UEPB

\begin{abstract}
RESUMO: O semiárido brasileiro destaca-se pelo seu clima quente e seco, cujos índices de precipitação são restritos a poucos meses do ano. Localizada nessa região, a cidade de Itaporanga, no estado da Paraíba foi objeto do presente estudo, que objetivou verificar a variabilidade pluviométrica da microrregião, através da análise espaçotemporal mensal e anual da precipitação, identificando-se os períodos secos e chuvosos da área em análise através do Índice de Anomalia de Chuva (IAC). Foram utilizados 12 postos pluviométricos distribuídos nos municípios da microrregião de Itaporanga, que correspondem ao período de 1994 e 2017. Observa-se, através do estudo, que a microrregião apresenta períodos pluviométricos distintos, um período chuvoso ocorrendo entre os meses de janeiro e maio, sendo o mês de março o mais representativo, atingindo uma precipitação média de $201,0 \mathrm{~mm}$, e outro período seco ocorrendo entre os meses de junho e dezembro, sendo setembro o mês mais seco, com média de $1,8 \mathrm{~mm}$ de precipitação. Os resultados indicam uma eficiência no uso do índice IAC evidenciando as anomalias de precipitação para a região em estudo, demonstrando ser uma metodologia eficiente para monitoramento ambiental dos períodos extremos de precipitação através da série histórica analisada.
\end{abstract}

PALAVRAS-CHAVE: Precipitação, Índice de Anomalia de Chuva, Períodos chuvosos e secos

PLUVIOMETRIC VARIABILITY IN THE MICRO-REGION OF ITAPORANGA, IN THE STATE OF PARAÍBA

ABSTRACT: The Brazilian semiarid region stands out for its hot and dry climate, whose precipitation rates are restricted to a few months of the year. Located in this region, the city of Itaporanga, in the state of Paraíba was the object of the present study, which aimed to verify the rainfall variability of the micro-region, through the monthly and annual spatial-temporal analysis of precipitation, identifying the dry and rainy periods of the area under analysis through the Rainfall Anomaly Index (IAC). Twelve pluviometric stations were used, distributed in the municipalities of the Itaporanga micro-region, corresponding to the period of 1994 and 2017. It is observed, through the study, that the micro-region presents different rainfall periods, a rainy period occurring between the 
months of January and May, the month of March being the most representative, reaching an average precipitation of $201 \mathrm{~mm}$, and another dry period occurring between the months of June and December, with September being the driest month, with an average of $1.8 \mathrm{~mm}$ of precipitation. The results indicate an efficiency in the use of the IAC index, evidencing the precipitation anomalies for the region under study, demonstrating to be an efficient methodology for environmental monitoring of extreme periods of precipitation through the analyzed historical series.

KEYWORDS: Precipitation, Rainfall Anomaly Index, Rainy and dry periods.

VARIABILIDAD PLUVIOMÉTRICA EN LA MICRO-REGIÓN DE ITAPORANGA, EN EL ESTADO DE PARAÍBA

RESUMEN: La región semiárida brasileña se destaca por su clima cálido y seco, cuyas tasas de precipitación están restringidas a unos pocos meses del año. Ubicada en esta región, la ciudad de Itaporanga, en el estado de Paraíba, fue objeto del presente estudio, el cual tuvo como objetivo verificar la variabilidad pluvial de la microrregión, a través del análisis espacio-temporal mensual y anual de precipitación, identificando los períodos secos y lluviosos del área bajo análisis a través del Índice de Anomalías de Lluvia (IAC). Se utilizaron doce estaciones pluviométricas, distribuidas en los municipios de la microrregión de Itaporanga, correspondientes al período de 1994 y 2017. Se observa, a través del estudio, que la microrregión presenta diferentes períodos de lluvias, un período lluvioso que ocurre entre los meses de enero y mayo, siendo el mes de marzo el más representativo, alcanzando una precipitación promedio de $201 \mathrm{~mm}$, y otro período seco ocurre entre los meses de junio y diciembre, siendo septiembre el mes más seco, con un promedio de $1.8 \mathrm{~mm}$ de precipitación. Los resultados indican una eficiencia en el uso del índice IAC, evidenciando las anomalías de precipitación para la región en estudio, demostrando ser una metodología eficiente para el monitoreo ambiental de períodos extremos de precipitación a través de la serie histórica analizada.

PALABRAS CLAVE: Precipitación, Índice de anomalías de lluvia, Períodos

\section{INTRODUÇÃO}

O semiárido brasileiro destaca-se pelo seu clima quente e seco, com temperaturas em torno de $27^{\circ} \mathrm{C}$, abrangendo os nove estados do Nordeste Brasileiro (Alagoas, Bahia, Ceará, Maranhão, Paraíba, Pernambuco, Piauí, Rio Grande do Norte e Sergipe) (NEB) e o norte do estado de Minas Gerais. Logo, os fatores ambientais como as condições climáticas, a vegetação e a hidrologia são de extrema importância para compreensão do ambiente e podem ter representações significativas nas atividades humanas.

Deste modo, o conhecimento das características climáticas e suas projeções são essenciais, visto que evidenciam mudanças na precipitação e nas temperaturas do ar do NEB, fato que está intimamente associado a disponibilidade hídrica e as condições de adaptação das culturas (SALES et al. 2015; GUIMARÃES et al. 2016).

Além disso, o semiárido apresenta um grande déficit hídrico, causado pela irregularidade na distribuição da precipitação espaço temporal. Nesta região, é frequente a ocorrência de secas no período que é considerado chuvoso que, dependendo da intensidade e duração, provoca redução da produção em áreas da agricultura familiar, impactos ambientais, econômicos, sociais e promove migrações de famílias para áreas urbanas (SANTIAGO et al. 2013; HAGENLOCHER et al., 2019; MEZA et al., 2019).

O Clima da região semiárida nordestina, destaca-se como um fator determinante para o desenvolvimento da região e sua variação espaço- 
temporal decorre de uma combinação de fatores atmosféricos em escala de magnitude global, regional e local (MANOSSO et al. 2013).

Os fenômenos oriundos da variabilidade climática na precipitação pluvial, devido às mudanças climáticas, podem acarretar um aumento significativo de eventos extremos de períodos secos e chuvosos (COSTA et al. 2015).

Logo, os sistemas atmosféricos atuantes que interferem de forma significativa na precipitação pluvial (chuva) no NEB são eles: Distúrbios nos Ventos Alísios (DVA), Linhas de Instabilidade (LI), Sistemas Frontais (SF), Vórtices Ciclônicos em Altos Níveis (VCAN), Zona de Convergência do Atlântico Sul - (ZCAS) e a Zona de Convergência Intertropical (ZCIT) NÓBREGA e SANTIAGO, 2014; ASSIS et al. 2015; PALHARINI e VILA, 2017).

Desse modo, Francisco et al. (2015) afirmam que a região do Cariri/Curimataú é a parte do estado da Paraíba que menos chove, na ordem de $300 \mathrm{~mm}$ a $500 \mathrm{~mm}$, no Sertão e no Alto Sertão ocorre em torno de 700 $\mathrm{mm}$ a $900 \mathrm{~mm}$, no Brejo e no Agreste as precipitações variam de $700 \mathrm{~mm}$ a $1200 \mathrm{~mm}$, e o Litoral apresenta as maiores médias pluviométricas, alternadas entre $1.200 \mathrm{~mm}$ a $1.600 \mathrm{~mm}$.

Nascimento et al. (2019) afirmam que essa precipitação ocorre em maior intensidade no litoral e agreste por conta do oceano Atlântico. Já o sertão, recebe uma boa quantidade de chuvas devido à ZCIT. Por outro lado, no Cariri e Curimataú, as precipitações são menores devido ao Planalto da Borborema, que serve de obstáculo que dificulta a passagem das chuvas oriundas o oceano Atlântico.

Deste modo, o impacto causado pelo fenômeno El Niño e La Niña no NEB dependendo da sua intensidade pode resultar em secas ou enchentes severas, interferindo de forma significativa nas atividades econômicas (SOUSA et al. 2015).

Já no trabalho de Nóbrega et al. (2016), o mesmo fez uma correlação por modelos estatísticos entre a relação dos oceanos e as chuvas no NEB, com o auxílio do IAC, foi possível evidenciar que através da análise estatística sobre o oceano Pacífico e Atlântico permitiu demonstrar que há uma tendência de aquecimento e que, quando analisados isoladamente a ocorrência de anomalias positivas sobre o Pacífico leste (El Niño) e anomalias negativas sobre o Atlântico Sul (dipolo positivo), as secas são mais severas.

Diante dessa variabilidade na precipitação, faz-se necessário o monitoramento contínuo por meio de técnicas eficazes que possibilitem o aprimoramento dos estudos hidrológicos. Dentre as técnicas disponíveis, o emprego de índices climáticos tais como Índice de Severidade de Seca de Palmer - PDSI (PALMER, 1965); O Índice de Seca de Bhalme e Mooley BMDI (BHALME \& MOOLEY, 1980); O Índice de Desvio de Chuva de Lamb LRDI (LAMB et al. 1986); O Índice de Precipitação Padronizada - SPI (McKEE et al. 1993) tem se mostrado eficaz para o acompanhamento dos períodos secos e chuvosos, contemplando informações anuais, sazonais ou mensais (DA SILVA, 2009). 
Desse modo, pode-se compreender como as precipitações de cada região, estado ou município se estabelecem, proporcionando o manejo adequado dos recursos hídricos (SILVA FILHO et al. 2015).

Para esse fim, o presente estudo utiliza o Índice de Anomalia de Chuva (IAC) como uma ferramenta capaz de caracterizar bem a variabilidade temporal das precipitações anual e mensal na microrregião de Itaporanga, identificando os períodos secos e chuvosos, gerando subsídios para o aprimoramento do gerenciamento dos recursos hídricos locais.

De acordo com Araújo e Da Silva (2011), a vantagem do IAC é que, diferentemente de outros índices, ele precisa apenas de dados de precipitação e é de fácil estimativa. Sendo um conhecimento que colabora para estudos de verificação dos impactos do clima global sobre a vulnerabilidade da classificação pluviométrica no planeta (ARAÚJO et al. 2009).

Além disso, outros estudos afirmam que o IAC é o mais adequado para o NEB, pela caracterização da variabilidade espaço-temporal da precipitação, apresentando-se como um bom indicador climático para caracterizar os períodos chuvosos e secos (MANIÇOBA et al. 2017; NASCIMENTO et al. 2020).

Diante do exposto, o objetivo principal deste trabalho é verificar e avaliar a variabilidade pluviométrica da microrregião de Itaporanga, através da análise espaço-temporal mensal e anual da precipitação, identificando-se assim os períodos secos e chuvosos da área estudada com o auxílio do IAC.

\section{MATERIAIS E MÉTODOS}

\section{ÁREA DE ESTUDO}

O presente trabalho tem como a área de estudo a microrregião de Itaporanga (Figura 1) que pertence a mesorregião do Sertão Paraibano - PB. Sua população foi estimada em 2017 pelo IBGE em 86809 habitantes e possui uma área total de $3053,939 \mathrm{~km}^{2}$, estando dividida em onze municípios: Boa Ventura, Conceição, Curral Velho, Diamante, Ibiara, Itaporanga, Pedra Branca, Santa Inês, Santana de Mangueira, São José de Caiana e Serra Grande. Logo, o mapa de localização foi realizado no Software QGIS Versão 3.10.12-A Coruña que pertence a mesorregião do Sertão Paraibano - PB. 


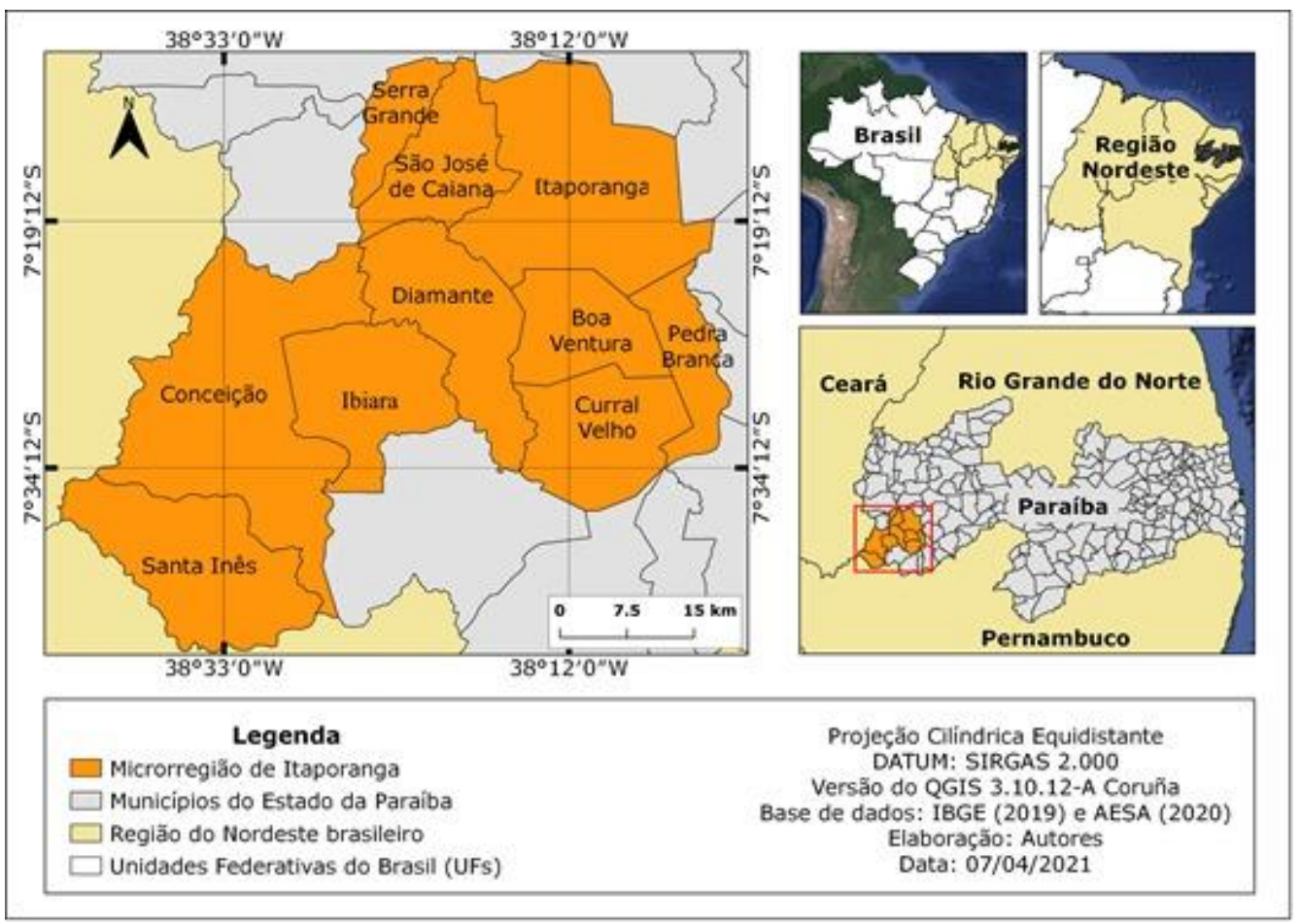

Figura 1 - Localização dos municípios da Microrregião de Itaporanga. Fonte: Elaborado pelo autor

\section{DADOS PLUVIOMÉTRICOS}

Os dados pluviométricos utilizados na pesquisa correspondem as séries mensais de precipitação no período de 1994 a 2017 fornecidos pela Agência Executiva de Gestão das Águas do Estado da Paraíba (AESA). Os dados foram disponibilizados e processados no Excel versão 16.0, separado os postos pluviométricos em planilhas eles serviram como base para a análise espaço-temporal.

Neste sentido, foram utilizados 12 pontos meteorológicos localizados dentro dos 11 municípios da microrregião estudada, de acordo com o Quadro 1. Para esse levantamento, foram realizados os seguintes procedimentos: em cada planilha foi tirada a média histórica do município no período da série em estudo, posteriormente foram colocados em uma nova planilha todos os 12 postos já com a média dos 24 anos de cada município.

Assim sendo, quando foram colocados nessa única planilha, se tirou a média histórica da microrregião e disponibilizado para fazer o estudo temporal, e posteriormente da espacialização.

Para a interpolação desses dados mensais e anuais da série cronológica, foi utilizado o software Surfer 8.0 na geração dos mapas acumulado e mensal da espacialização da microrregião de Itaporanga. Neste sentido, foi utilizado o método da Krigagem Ordinária, um modelo geoestatístico que consiste em interligar os pontos circunvizinhos. 
O semivariograma é a parte central dos estudos geoestatísticos, sendo capaz de descrever tanto qualitativa quanto quantitativamente a variação espacial, além de ser o ponto chave na determinação do preditor geoestatístico-krigagem.

Quadro 1 - Identificação (ID) das estações pluviométricas municípios da Microrregião de Itaporanga, coordenadas geográficas, latitude $\left({ }^{\circ}\right)$, longitude $\left({ }^{\circ}\right)$, percentual de falhas nos dados (\%) e período da série temporal.

\begin{tabular}{|c|c|c|c|c|c|}
\hline \multirow{2}{*}{ ID } & \multirow{2}{*}{ Estações } & Lat. & Long. & \% Falhas & \multirow[b]{2}{*}{ Período } \\
\hline & & $(0, \mathbf{S})$ & $(0, W)$ & nos Dados & \\
\hline 1 & Boa Ventura & $-7,42$ & $-38,21$ & 0,0 & $1994-2017$ \\
\hline 2 & Conceição & $-7,56$ & $-38,50$ & 0,0 & $1994-2017$ \\
\hline 3 & Curral Velho & $-7,53$ & $-38,19$ & 3,0 & $1994-2017$ \\
\hline 4 & Diamante & $-7,42$ & $-38,26$ & 2,8 & $1994-2017$ \\
\hline 5 & Ibiara & $-7,50$ & $-38,40$ & 0,0 & $1994-2017$ \\
\hline 6 & Itaporanga & $-7,30$ & $-38,15$ & 0,0 & $1994-2017$ \\
\hline 7 & Itaporanga-Fz, Veludo & $-7,36$ & $-38,20$ & 5,0 & $1994-2017$ \\
\hline 8 & Pedra Branca & $-7,41$ & $-38,06$ & 2,8 & $1994-2017$ \\
\hline 9 & Santa Inês & $-7,62$ & $-38,55$ & 6,0 & $1994-2017$ \\
\hline 10 & Santana de Mangueira & $-7,55$ & $-38,33$ & 0,0 & 1994-2017 \\
\hline 11 & São José de Caiana & $-7,25$ & $-38,29$ & 2,8 & $1994-2017$ \\
\hline 12 & Serra Grande & $-7,21$ & $-38,37$ & 0,0 & 1994-2017 \\
\hline
\end{tabular}

Fonte: Elaborado pelo Autor

Ressalta-se ainda, que ao longo da série histórica de dados foram encontradas algumas lacunas, porém que não representaram alterações significativas nos resultados. Desse modo, as lacunas encontradas foram mínimas, o que possibilitou o não preenchimento dos dados.

De acordo com Nikolova (2007), essas lacunas não devem ser preenchidas, pois a reposição de valores em falta na série histórica de precipitação ocasiona mais subjetividade à investigação.

\section{DECLIVIDADE E HIPSOMETRIA DA MICRORREGIÃO}

Para a realização do diagnóstico de declividade e hipsometria da microrregião de Itaporanga foi utilizado uma imagem de radar (SRTM Shuttle Radar Topography Mission) com resolução espacial de 30 metros, referente às folhas SB-24-Z-C disponibilizadas no site TOPODATA. Gerados automaticamente em ambiente SIG no software QGIS Desktop 2.18.0 e expresso em valores percentuais. A partir da imagem SRTM foram extraídas as curvas de nível, com intervalo de 10 metros, que variaram de 0 a 750 metros. 
Assim as análises das bases cartográficas, a elaboração dos mapas hipsométricos e de declividade, permitem a visualização das altitudes e cotas mínimas e máximas da área em estudo (RODRIGUES et al. 2020). Logo, através das curvas de nível foram gerados os mapas de declividade $e$ hipsometria.

Para o mapa hipsométrico, foram estabelecidas 8 classes de altimetria que mais se adequam a área de estudo, assim obtém-se uma visão do relevo, caracterizando as suas áreas de planícies aluviais e as demais formas do relevo (SOARES; PIROLI, 2019). Associando-as ao Modelo Digital de Elevação (MDE) e o relevo sombreado foi gerado o mapa de hipsometria com os valores de elevação do terreno.

O mapa de declividade foi elaborado a partir da imagem SRTM com os valores de declividade em porcentagem. Foram estabelecidas 5 classes de declividade descritas na Tabela 1 (EMBRAPA, 1979), que numa rampa de cores varia entre o verde para o menor declive e vermelho para o maior valor de declividade, facilitando assim á interpretação dos dados gerados.

Tabela 1 - Classes de declividade em valores percentuais. Fonte: EMBRAPA, 1979.

\begin{tabular}{ll}
\hline Declividade (\%) & Classes \\
\hline $0-3$ & Plano \\
$3-8$ & Suave ondulado \\
$8-20$ & Ondulado \\
$20-45$ & Fortemente ondulado \\
$45-75$ & Montanhoso \\
\hline
\end{tabular}

\section{APLICAÇÃO DO MÉTODO IAC}

A análise da duração dos períodos secos e úmidos será realizada por meio do cálculo do IAC anual desenvolvido e utilizado por Rooy (1965), e adaptado por Freitas, (2005), obtido a partir das Equações 1 e 2 que representa as anomalias positivas (Equação 1) e negativas (Equação 2), respectivamente, onde: $N$ é a precipitação mensal atual $(\mathrm{mm}) ; \bar{N}$ é a precipitação média mensal da série histórica $(\mathrm{mm}) ; \bar{M}$ é a média das dez maiores precipitações mensal da série histórica $(\mathrm{mm}) ; X$ é a média das dez menores precipitações mensais da série histórica $(\mathrm{mm})$.

$$
\begin{gathered}
I A C=3\left[\frac{(N-\bar{N})}{(\bar{M}-\bar{N})}\right]: \text { Equação } 1 \\
I A C=-3\left[\frac{(N-\bar{N})}{(\bar{X}-\bar{N})}\right]: \text { Equação } 2
\end{gathered}
$$

Sob o ponto de vista climatológico, as séries históricas coletadas nesse estudo são consideradas curtas, no entanto, de acordo com Dos Santos et al. (2011), elas nos permitem formular hipóteses sobre tendências de aumento ou redução das chuvas em condições atmosféricas extremas.

Conforme os mesmos autores, recomenda-se uma série histórica de no mínimo 30 anos de dados para se aplicar o IAC, caso a série seja menor, deve-se adaptar a quantidade de médias utilizadas para se calcular o IAC, 
modificando proporcionalmente a quantidade de dados disponíveis. Portanto, para uma série de dados de 24 anos, foram calculadas as médias das 8 maiores e as 8 menores precipitações totais do período analisado. Depois de efetivado o cálculo do IAC, os valores gerados foram classificados de acordo com sua intensidade (Tabela 2).

Tabela 2 - Classes de intensidades do índice de anomalia de chuva (IAC) da Microrregião de Itaporanga. Fonte: Araújo et al. (2009).

\begin{tabular}{ll}
\hline FAIXA DO IAC & CLASSES DE INTENSIDADE \\
\hline Acima de 4 & Extremamente úmido \\
2 a 4 & Muito úmido \\
0 a 2 & Úmido \\
0 a -2 & Seco \\
-2 a -4 & Muito seco \\
Abaixo de -4 & Extremamente seco \\
\hline
\end{tabular}

\section{RESULTADOS E DISCUSSÕES}

$\mathrm{Na}$ Figura 2, é possível observar dois períodos distintos, um de cinco meses chuvoso e outro com sete meses secos. O chuvoso ocorre entre os meses de janeiro a maio com precipitação que variam entre $(76,0 \mathrm{~mm}$ a $210,0 \mathrm{~mm})$, sendo o mês de março $(201,00 \mathrm{~mm})$ o mais representativo.

A ZCIT que atua com maior frequência entre os meses de fevereiro a maio, ocasiona uma maior intensidade de chuvas na região, porem o seu ápice ocorre no mês de março nesta área (UVO, 1989). Em contrapartida, o período seco ocorre entre os meses de junho a dezembro, tendo setembro o mês mais seco, com média de $1,8 \mathrm{~mm}$ de precipitação.

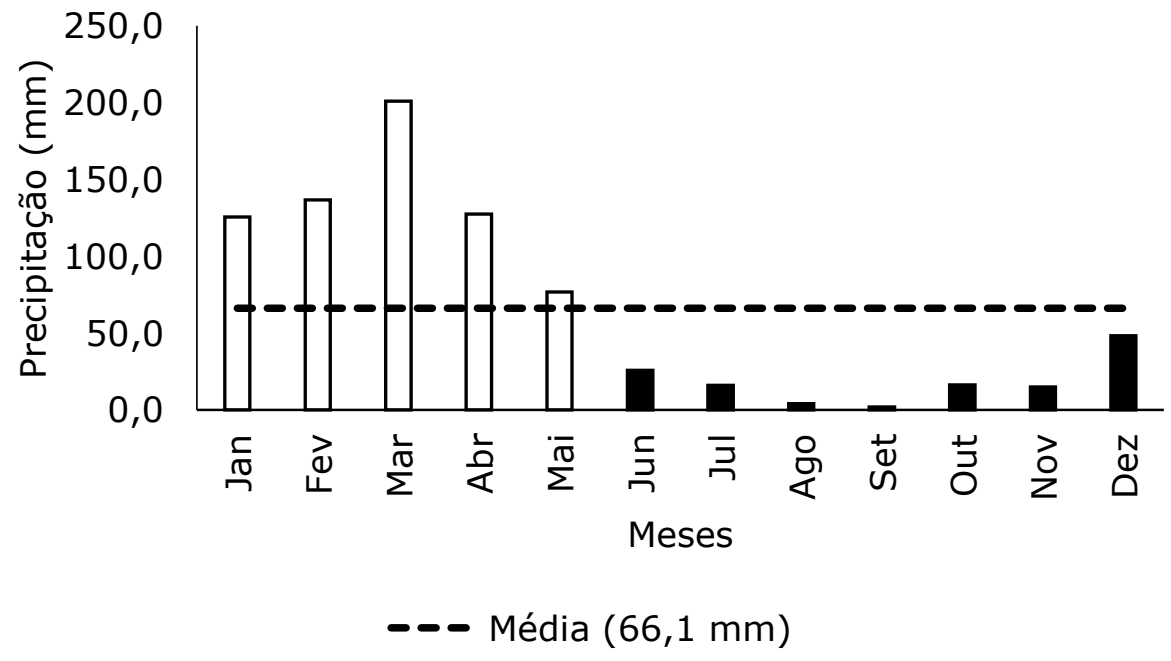

Figura 2 - Pluviograma de Precipitação mensal da área da Microrregião de Itaporanga. Fonte: Elaborado pelo autor

A distribuição da precipitação média da microrregião de Itaporanga se destaca na Figura 3, na qual 84 \% da precipitação faz parte do período úmido, portanto o conhecimento dessas informações pode ajudar a compreender os benefícios que essas chuvas trazem nesse período para a região. Deste modo, a 
chuva em determinada época do ano pode ser útil ou prejudicial à agricultura, dependendo se coincide com o período vegetativo ou de colheita de determinadas culturas (SANTOS \& SOUZA, 2018).

Além disso, o volume precipitado da chuva que ocorre no período chuvoso, está ligado diretamente com a qualidade de água encontrado nas mais diversas regiões do país. Assim, um fato que pode ser notado é que as regiões que sofrem com essa qualidade de água são as áreas semiáridas.

Portanto, no Brasil, observou-se que a menor qualidade das águas, estão em áreas metropolitanas e em alguns açudes do Semiárido quando comparados a outras regiões do país (ANA, 2019). Assim sendo, os resultados contribuam para o planejamento municipal dos recursos hídricos, para diminuir os impactos qualidade das águas de rios e lagoas e, consequentemente, à saúde pública e equilíbrio dos ecossistemas (ROSA et al. 2016).

Por outro lado $16 \%$, da precipitação da microrregião encontra-se presente no período seco. Com isso, políticas públicas podem ser desenvolvidas com o intuito de promover a preservação de água nos municípios, prevenindo a escassez durante as secas ou estiagens.

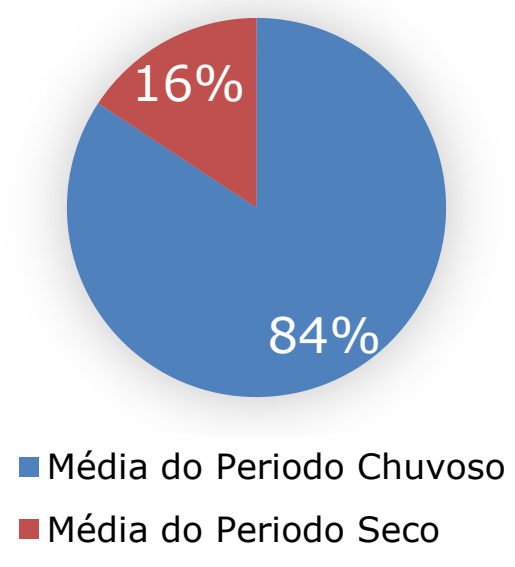

Figura 3 - Percentual da precipitação da Microrregião de Itaporanga nas estações seca e chuvosa. Fonte: Elaborado pelo autor

Através da criação do Triangulated Irregular Network (TIN) foi possível obter os mapas de hipsometria (MDE), cujo produto representa a altitude do terreno através de cores. Segundo o mapa hipsométrico a altitude da microrregião varia de $276 \mathrm{~m}$ a $884 \mathrm{~m}$, apresentando como destaques as áreas com maiores altitudes, localizadas nas regiões Norte, Oeste e Sul enquanto as regiões Nordeste, Leste e Sudoeste apresentam uma suavidade no relevo, com áreas de baixo altitude, variando entre $200 \mathrm{~m}$ e $400 \mathrm{~m}$ (Figura 4). 


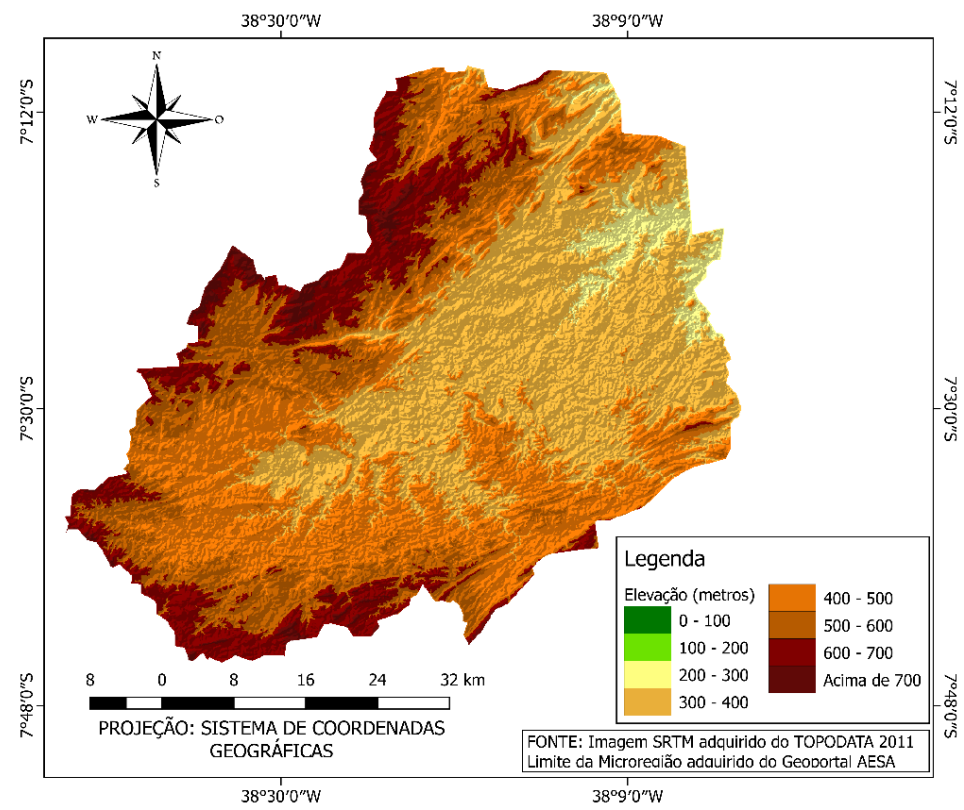

Figura 4 - Hipsometria da Microrregião de Itaporanga- PB, Brasil. Fonte: Elaborado pelo autor

O mapa da declividade (Figura 5), demonstra as inclinações da área em relação a um eixo horizontal. Pôde ser constatado, que as áreas onde houve maior variação de elevação, coincidiram com as que obtiveram uma mais elevada (Figura 4). Logo, o mapa de declividade é permitido a visualização das relações entre os diferentes graus de declividade e sua posição na vertente, identificando desta forma o padrão de áreas com maior suscetibilidade a erosão e com maior fragilidade natural (COLAVITE; DOS PASSOS, 2012).

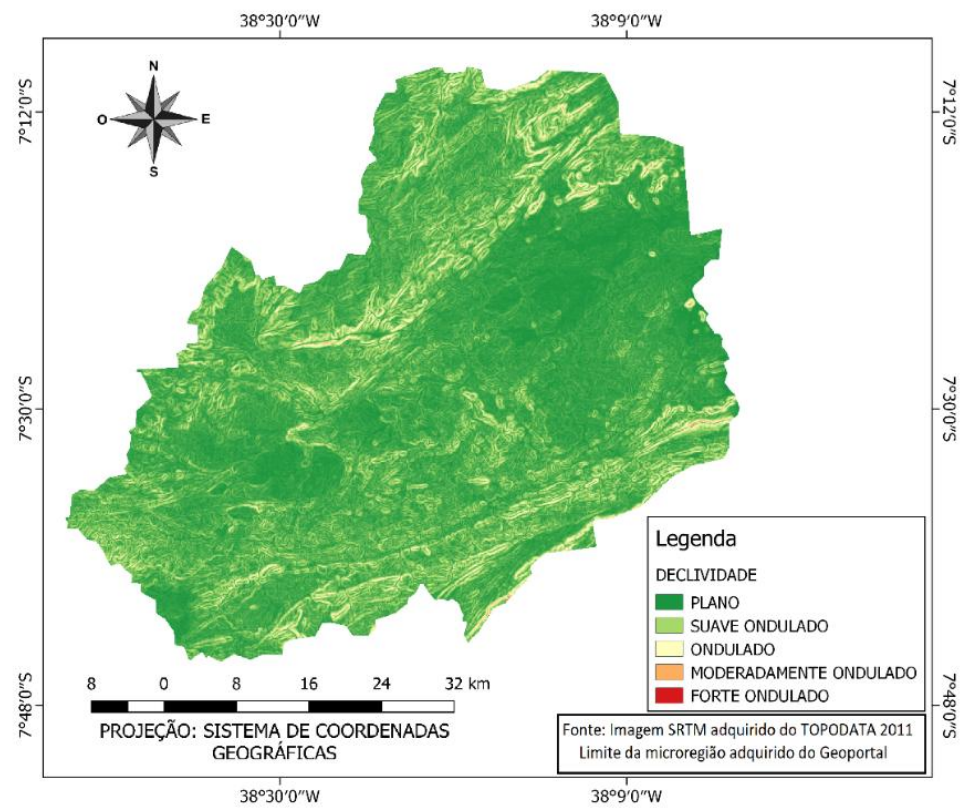

Figura 5 - Declividade da Microrregião de Itaporanga -PB, Brasil. Fonte: Elaborado pelo autor 
Com o mapa de declividade, foi observado que a área apresenta poucas ondulações, onde houve maior estabilidade, com declividade variando entre $0 \%$ e $10 \%$ (Plano e Suave Ondulado), representando cerca de $65 \%$ da microrregião.

Deste modo, $35 \%$ da área de estudo ficou entre os declives de $11 \%$ a $45 \%$ (Ondulado e Moderadamente Ondulado), com destaque principalmente ao Ondulado, que ficou concentrado especialmente nos topos de morro, constituindo platôs de superfície bastante regular e uma parte em pequenas planícies de base local.

A espacialização da precipitação acumulada da Microrregião de Itaporanga, (Figura 6), verificou-se que os maiores valores de precipitação são observados ao norte com valores variando de $880 \mathrm{~mm}$ a $910 \mathrm{~mm}$. É notório que através da imagem ao longo da microrregião a precipitação diminui no sentido de norte a sul, tornando-se assim a área com menos abundância de chuvas atinge valores de $700 \mathrm{~mm}$.

Assim sendo, essa distribuição na precipitação ajuda a entender de que forma as chuvas se portam ao longo da microrregião, ajudando na compreensão dos fenômenos hidrológicos relacionados a precipitação e no gerenciamento dos recursos hídricos locais.

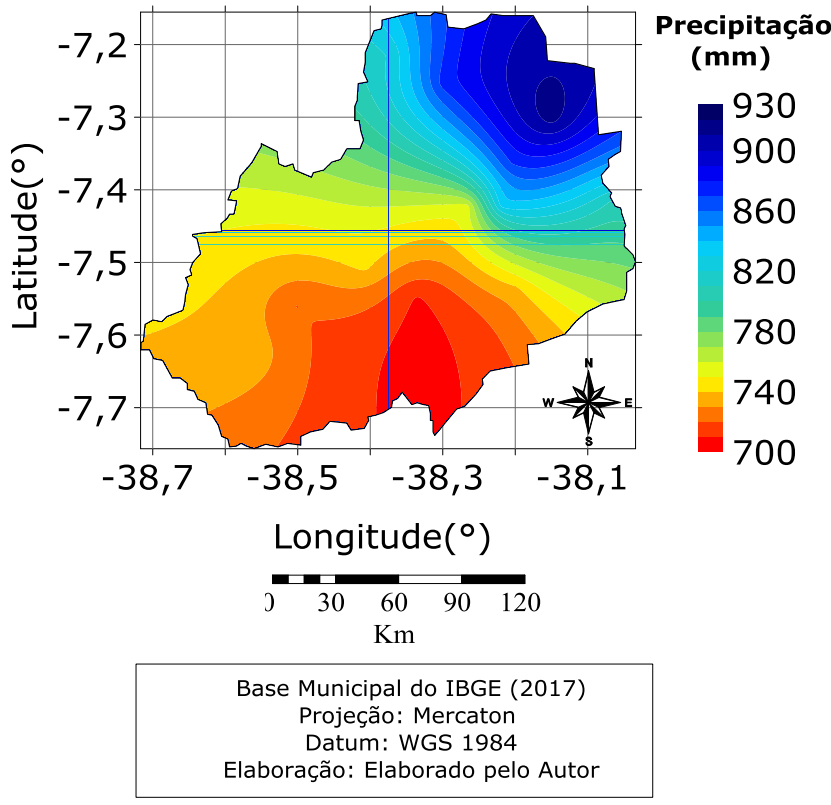

Figura 6 - Distribuição espacial da precipitação acumulada da microrregião de Itaporanga. Fonte: Elaborado pelo autor

Vale destacar que a precipitação acumulada da microrregião de Itaporanga (Figura 6), em comparação com o mapa hipsométrico (Figura 4), mostra que o relevo influencia em certos pontos da área Sul e Sudoeste que apresentaram um menor índice pluviométrico significando assim a área mais seca. Por outro lado, o relevo não influenciou em certos pontos, como na parte Norte mesmo com uma altitude elevada obteve-se um bom índice pluviométrico. 
Destaca-se ainda, que onde o relevo apresentou menor altitude foram locais de maiores precipitações, mostrando assim que no decorrer de algumas áreas o relevo pode influenciar diretamente na pluviosidade da microrregião estudada. Deste modo, o relevo acentuado e com grande variação da declividade é um dos aspectos que depreende sumária atenção, visto que, determinados eventos podem desencadear importantes impactos, como as chuvas em uma determinada localidade, além de ser um dos principais fatores da heterogeneidade das chuvas em determinada região (FORGINARI et al. 2014; TAVARES \& FERREIRA, 2020).

$\mathrm{Na}$ finalidade de melhor entender o comportamento dinâmico da precipitação analisou-se a espacialização da precipitação da microrregião de Itaporanga mensalmente (Figuras 7A a 7L).

Nas isoietas médias mensais da microrregião de Itaporanga foram demonstradas o comportamento da precipitação de janeiro a dezembro. O mês de janeiro (Figura 7A) representa o início do período chuvoso, onde os seus maiores valores estão localizados na porção nordeste, atingindo 153,4 $\mathrm{mm}$, enquanto seus menores localizam-se no sudoeste da microrregião, com cerca de 75,0 mm. O mês de fevereiro (Figura 7B) apresentou-se com precipitações acima de $109 \mathrm{~mm}$ na parte sul e ao norte com 162,0 mm.

O mês de março (Figura 7C), no qual é de extrema importância para a microrregião, visto que é o de maior volume em termos de precipitação, assim é necessitando ter um olhar mais crítico e firme no gerenciamento dos recursos hídricos por parte dos órgãos competentes, para que esse recurso permaneça durante durante o período de escassez. Portanto, notou-se que seus índices estão distribuídos tendo os menores localizados no sul (por volta de $181,8 \mathrm{~mm}$ ) e o resto dos municípios com precipitações acima de 220,0 $\mathrm{mm}$, atingindo seu ápice entre o norte e o leste.

No mês de abril (Figura 7D), a chuva se distribuiu bem em toda microrregião, porém a parte menos abundante foi a região central, com 98 $\mathrm{mm}$, enquanto os maiores valores foram encontrados ao norte, com 159,4 $\mathrm{mm}$. Já o mês de maio (Figura 7E), último mês da estação chuvosa e mês de transição para o período seco da microrregião estudada, apresentou $50,0 \mathrm{~mm}$ a 103,0 mm, onde ficou evidente que a área sul foi a de menor precipitação e em um ponto da parte nordeste.

Foi observado que no mês de junho (Figura 7F), inicia a estação seca da microrregião, deste modo, ocorreu uma diminuição considerável de sua precipitação ao longo dos municípios, onde foi possível evidenciar que os maiores valores foram localizados na parte norte, com cerca de $38,0 \mathrm{~mm}$, e os menores na área sul e sudeste, com 15,0 mm. Já o mês de julho (Figura $7 G)$, observa-se que os seus maiores índices foram localizados em pequenos pontos na área mais ao norte e nordeste com $21,0 \mathrm{~mm}$ de precipitação e os seus menores no decorrer de toda a área de estudo com 11,0 mm.

Porém os meses de agosto (Figura 7H) e setembro (Figura 7I), a precipitação diminuiu gradativamente em todos os municípios, sendo esses os 2 meses mais secos da área de estudo, quando foram registrados no mínimo $0,1 \mathrm{~mm}$ e no máximo de $8,0 \mathrm{~mm}$ distribuídos na microrregião. Da mesma forma, é necessário um maior gerenciamento dos recursos hídricos 
pelos órgãos competentes nesse período objetivando o contínuo abastecimento de água para a população.

Portanto, a falta da precipitação pluviométrica pode resultar em alterações no regime de vazões mínimas em rios, resultando em uma diminuição da confiabilidade de sistemas de abastecimento de água e de irrigação, além de provocar agravos na capacidade de geração de energia hidrelétrica (SOUZA, et al. 2020).

Além disso, os impactos provenientes das secas, podem desestabilizar a subsistência de populações que vivem em terras áridas ou semiáridas, podendo levar a uma crise de desenvolvimento humano invisível e ao processo de migração (UNCCD, 2014; VERNER, 2016).

Para o mês de outubro (Figura 7J), a distribuição das chuvas encontra-se com os maiores valores localizados na parte sudoeste, atingindo $32,1 \mathrm{~mm}$, e seus menores na parte central da microrregião cortando de leste a oeste com 9,5 mm. Já o mês de novembro (Figura 7K), a distribuição ficou mais homogênea, sendo as partes leste e sul com maiores valores $21,0 \mathrm{~mm}$ e as partes norte e oeste com menores índices pluviométricos atingindo 5,0 $\mathrm{mm}$.

Já o mês de dezembro (Figura 7L) proporcionou um amplo aumento na precipitação, comparado aos meses anteriores, tendo em vista que esse mês é o de transição do período seco para o chuvoso. Nota-se que os maiores foram encontrados na parte central e principalmente a sudoeste com precipitação em 58,0 mm, enquanto os menores ocorreram em alguns pontos dentro da microrregião sendo eles a norte, noroeste e um pouco próximo a região sudoeste com $42,0 \mathrm{~mm}$.

Logo, através do conhecimento desses resultados, possam colaborar para que gestores estaduais, municipais e agricultores tenham conhecimento dos períodos apontados e dos meses de maior fartura e insuficiência de água, mais favoráveis as atividades humanas, contribuindo assim para uma maior produtividade e estruturação do homem do campo.

Além disso, pode ser aplicado na região construções de cisternas para obtenção dessas águas, principalmente nos meses que necessitem de uma demanda maior, encontradas no período seco. Outro método seria a mudanças de hábitos, principalmente por se encontrarem na região semiárida, através de coleta de águas pluviais, uma melhora no saneamento básico e ecológico em pequenas comunidades nestes municípios, além de uma drenagem mais eficaz que sirva para levar as águas aos reservatórios e não causar alagamentos nestas áreas. 
Longitude $\left(^{\circ}\right)$
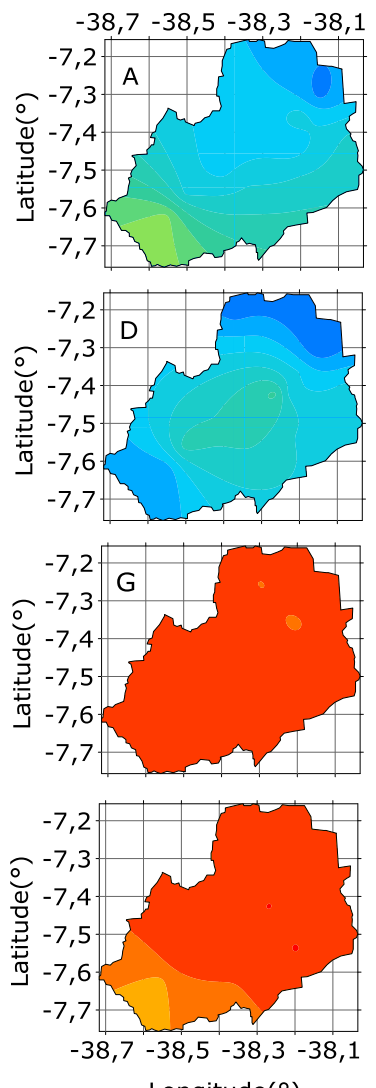

Longitude $\left({ }^{\circ}\right)$
Longitude $\left({ }^{\circ}\right)$
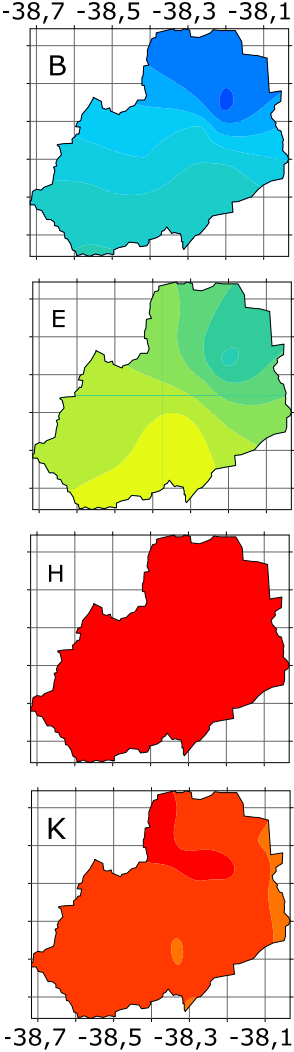

Longitude $\left(^{\circ}\right)$

Base Municipal do IBGE (2017)

Projeção: Mercaton

Datum: WGS 1984

Elaboração: Elaborado pelo Autor

Longitude $\left({ }^{\circ}\right)$

$-38,7-38,5-38,3-38,1$
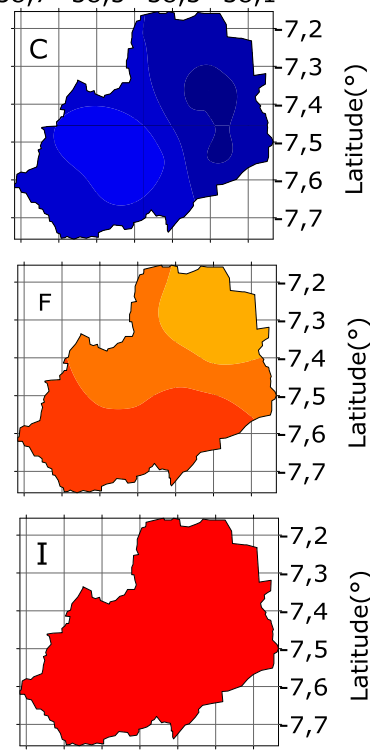

120

90

60

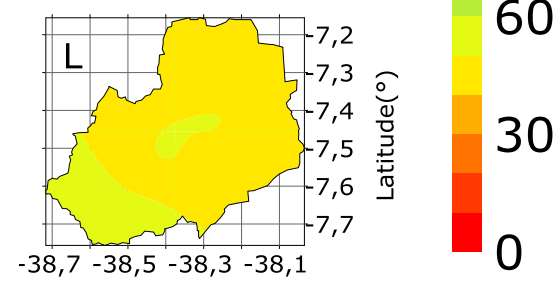

30

\section{Precipitação \\ (mm) \\ 210 \\ 180 \\ 150}

Longitude $\left({ }^{\circ}\right)$
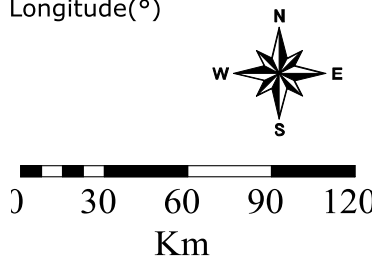

Figura 7 - Isoietas médias mensal da microrregião de Itaporanga de Janeiro $(A)$, Fevereiro (B), Março (C), Abril (D), Maio (E), Junho (F), Julho (G), Agosto (H), Setembro (I), Outubro (J), Novembro (K) e Dezembro (L). Fonte: Elaborado pelo autor

A Figura 8, a série pluviométrica é composta por treze anos chuvosos, que de acordo com a Tabela 2, são classificados como úmidos (1996, 1997, 2002, 2003, 2011 e 2013), muito úmido (1994, 1995, 2000, 2004, 2006 e 2010) e extremamente úmido (2008). Por outro lado, também foram encontrados onze anos secos, classificados como seco (1999, 2001, 2005, 2010, 2014 e 2017), muito seco (2007, 2015 e 2016) e extremamente seco (1998 e 2012).

Assim, através deste resultado é inegável notar dentro da escala do IAC anual que possuem variação na área estudada. Através de uma análise simples por meio de uma correlação os anos classificados como úmidos (6) e secos (6), obtém um somatório de 12 anos ou $50 \%$ e podemos classificá-los como estáveis e com pouco impacto significativo.

Já os anos classificados como muito úmidos (6) e muito secos (3), apresentaram juntos cerca de 9 anos ou 37,5 \%. De acordo com o resultado 
observado, pode-se ressaltar que os períodos úmidos podem originar eventos extremos nos municípios por falta de infraestrutura, estragos na agricultura entre outros atributos, corroborando de tal modo com Barbosa et al. (2016), que assegura que os eventos extraordinários de precipitação pluviométrica podem impactar em agravos na agricultura, problemas ambientais urbanos e, portanto, na saúde da população.

A crise hídrica está associada a escassez d'água na região, originando os períodos secos, prejudicando assim a agricultura e a criação de animais pela falta de chuvas, altas temperaturas, ocupação desordenada no solo, captações clandestinas, aumento da população e ausência de obras estruturantes por mais de 16 anos, pela falta de resiliência dos sistemas de abastecimento público e também pelo processo histórico de degradação das bacias hidrográficas (MARENGO E ALVES, 2015; MELO, 2016; GDF, 2018).

Como outra influência mútua ao meio ambiente, assim como afirma Wilhite (2003), todas as secas são causadas da deficiência de precipitação, que deriva na falta de água para o desenvolvimento de atividades ou para a sobrevivência dos seres vivos.

Os anos classificados como extremamente úmido (1) e extremamente seco (2) apresentaram apenas 3 anos ou 12,5\%, porem é nesses anos onde se deve possuir uma maior atenção. Destaca-se o ano de 1998 que apresentou um ano de El Niño forte, o que causou uma seca no NEB, acarretando em grandes agravos na região.

Com essa delimitação nestes anos destaca-se períodos de grandes impactos, tanto econômico, social e ambiental, em uma perspectiva de que as chuvas em excesso, trazem consigo problemas em grandes centros urbanos como, inundações, riscos de desastre ambientais, perca da lavoura e danos na saúde, caso não tenha uma gestão adequada dos recursos hídricos ou falta de conhecimento dos períodos em análise.

Por outro lado, as secas extremas provocam, além da pouca produtividade na agricultura, um aumento na temperatura, danos à saúde humana, mortalidade de animais, êxodo rural, dentre outros. Portanto, políticas que visem o abastecimento e manutenção desse bem natural (água) é imprescindível, visto que cerca de um bilhão de pessoas no mundo vive em bacias hidrográficas com escassez econômica de água (CIRILO, 2015). 


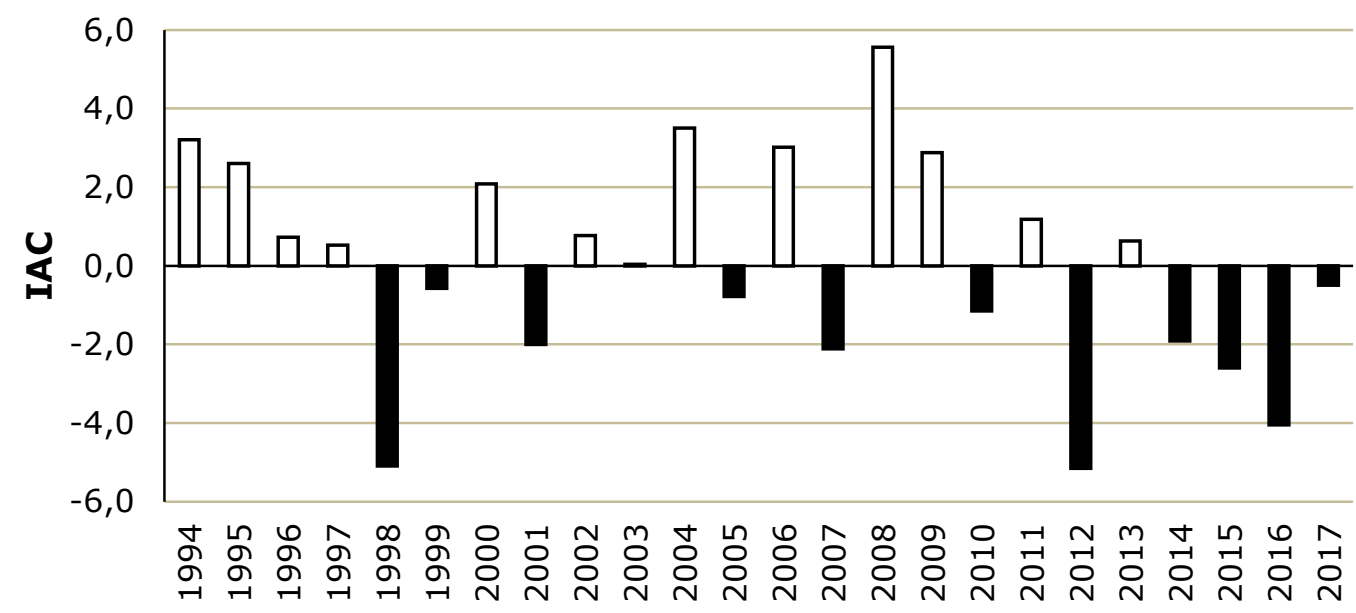

Anos

Figura 8 - Índice de anomalia de chuva (IAC) da Microrregião de Itaporanga. Fonte: Elaborado pelo autor

Durante a série histórica, foi constatado uma estabilidade entre o IAC com mudanças expressivas entre anos positivos e negativos, foi possível ainda demostrar que durante a série histórica os anos têm intervalos bem semelhantes, a cada ano úmido vem intercalados com anos secos. Além disso, é plausível destacar que em séries curtas ou longas de precipitação pluviométrica, o formidável é alternância entre períodos chuvosos e secos.

Portanto, quando a área em estudo demostra esse equilíbrio, nota-se que grandes mudanças não vêm ocorrendo ao longo dos anos, o que caracteriza que os impactos são mínimos. Além disso, é notório esse monitoramento para prever futuros cenários para a região, que apesar de não ter grandes impactos ao longo dos anos, sofreram com as secas em determinados períodos.

\section{CONSIDERAÇÕES FINAIS}

Os resultados da aplicação do estudo na região evidenciaram dois períodos distintos, um período chuvoso, que se estende de janeiro a maio, sendo março o mês com maiores precipitações; e outro, o período seco, que se estende de junho a dezembro, com setembro sendo o mês mais seco do período.

A climatologia espacial da microrregião de Itaporanga possui áreas específicas de distribuição de precipitação, sendo a porção nordeste com maior intensidade de chuvas. Em contrapartida a parte sul da microrregião é a porção mais seca. Em relação as isoietas mensais, evidenciou-se o mês de março como o de maior valor pluviométrico e os meses de agosto e setembro, sendo os meses de escassez.

Conclui-se ainda, que o IAC é uma ferramenta de extrema importância, pois demonstra que é passível de monitorar os períodos extremos, além disso pode verificar o comportamento de uma determinada região, município e/ou bacia hidrográfica. Portanto, o IAC, na microrregião de 
Itaporanga, demonstra uma alternância entre anos secos e úmidos de acordo com a série histórica.

Por fim, que os resultados obtidos possibilitem estratégias que contribuam para os gestores locais, agricultores e órgãos ambientais do estado, um conhecimento amplo dos períodos de maior escassez e de maior abundância dos recursos hídricos e dessa forma possibilitem projetar cenários futuros para o gerenciamento da região.

\section{REFERÊNCIAS BIBLIOGRÁFICAS}

Agência Nacional de Águas (Brasil). Conjuntura dos recursos hídricos no Brasil 2019: informe anual / Agência Nacional de Águas. -- Brasília: ANA, 2019.

ARAúJO, L. E.; MORAES, NETO, J. M.; SOOUSA, F. A. S. Análise Climática da Bacia do Rio Paraíba - Índice de Anomalia de Chuva (IAC). Engenharia Ambiental, v. 6, n. 3, p. 508-523, 2009.

ARAÚJO, L. E; DA SILVA. Influência da variabilidade climática sobre a distribuição espaço-temporal da precipitação no Baixo Paraíba (PB). Caminhos de Geografia, v. 12, p. 289-304, 2011.

ASSIS, J.M.O.; SOUZA, W.M.; SOBRAL, M.C.M. Climate analysis of the rainfall inthe lower-middle stretch of the São Francisco river basin based on the rain anomaly index. Revista Brasileira de Ciências Ambientais, v. 2, p. 188-202, 2015.

BARBOSA, V. V.; DE SOUZA, W. M.; GALVÍNCIO, J. D.; COSTA, V. S. O. Análise da variabilidade climática do município de Garanhuns, Pernambuco Brasil. Revista Brasileira de Geografia Física v. 9, n. 2, p. 353-367, 2016.

BHALME, H. N.; MOOLEY, D. A. Large-scale drought/floods and monsoon circulation. Monthly Weather Review, v. 108, n. 8, p. 1197-1211, 1980.

CIRILO, J. A. Crise Hídrica: Desafios e Superação. Revista USP, n. 106, p. 45$58,2015$.

COLAVITE, A. P.; DOS PASSOS, M.M. Integração de mapas de declividade e modelos digitais tridimensionais do relevo na análise da paisagem. revista geonorte, v. 3, n. 5, p. 1547-1559, 2012.

COSTA, M. S.; LIMA, K. C.; ANDRADE, M. M.; GONÇALVES, W. A. Tendências observadas em extremos de precipitação sobre a região Semiárida do Nordeste do Brasil. Revista Brasileira de Geografia Física, v. 8, n. 5, p. 1321$1334,2015$.

DA SILVA, D.F. Análise de aspectos climatológicos, ambientais, agro econômicos e de se seus efeitos sobre a Bacia hidrográfica do rio Mundaú (AL e PE). 2009. Tese de Doutorado em Recursos Naturais, Centro de Tecnologia e Recursos Naturais, Universidade Federal de Campina Grande, Campina Grande.

DOS SANTOS, E. P.; CORREIA, M. F.; ARAGÃO, M. R. S.; SILVA, F. D. S. Eventos extremos de chuva e alterações no regime hidrológico da Bacia Hidrográfica do Rio São Francisco: Uma aplicação do índice RAI (Rainfall Anomaly Index). Engenharia Ambiental, v. 8, p. 315-330, 2011. 
EMPRESA BRASILEIRA DE PESQUISA AGROPECUÁRIA - EMBRAPA. Serviço Nacional de Levantamento e Conservação de Solos (Rio de Janeiro, RJ). Súmula da 10. Reunião Técnica de Levantamento de Solos. Rio de Janeiro: 1979. 83p.

FORGINARI, F. R.; VENDRUSCULO, D. S.; RIZZI, E. S.; Análise de chuvas orográficas no centro do estado do Rio Grande do Sul. Ciência e Natura, v. 36, p. 193-200.

FRANCISCO, P. R. M; MEDEIROS, R.M; SANTOS, D; MATOS, R. M. Classificação Climática de Köppen e Thornthwaite para o Estado da Paraíba. Revista Brasileira de Geografia Física v. 8, n. 4, p. 1006-1016, 2015.

FREITAS, M. A. S. Um sistema de suporte à decisão para o monitoramento de secas meteorológicas em regiões semi-áridas. Revista Tecnologia, Fortaleza, v. suplem, p. 84-95, 2005.

GDF. Governo do Distrito Federal, 2018. Plano Integrado de Enfrentamento à Crise Hídrica. Brasília. Disponível: www.ibram.df.gov.br/images/Plano\%20integrado\%20de\%20enfrentamento\% 20da\%20crise\% 20h\%C3\%ADdrica.pdf. Acesso: 28 out. 2020.

GUIMARÃES, S.O.; COSTA, A.A., VASCONCELOS JÚNIOR, F.C.; SILVA, E.M.; SALES, D.C.; ARAÚJO JÚNIOR, L.M.; SOUZA, S.G. Projeções de Mudanças Climáticas sobre o Nordeste Brasileiro dos Modelos do CMIP5 e do CORDEX. Revista Brasileira de Meteorologia v. 31, p. 337-365, 2016.

HAGENLOCHER, M.; MEZA, I.; ANDERSON, C.C.; MIN, A. Drought vulnerabilityand risk assessments: state of the art, persistent gaps, and research agenda.

Environ. Res. Lett, v.14, 2019.

LAMB, P. J.; PEPPLER, R. A.; HASTENRATH, S. Interannual variability in the tropical atlantic. Nature, London, v. 322, n. 6076, p. 238-240, 1986.

MANIÇOBA, R. M.; SOBRINHO, J. E.; GUIMARÃES, Í. T.; JUNIOR. E. G. C.; SILVA. T. T. F.; ZONTA, J. H. Índice de anomalias de chuva para diferentes mesorregiões do Estado do Rio Grande do Norte. Revista Brasileira de Geografia Física, v. 10, n. 4, p. 1110-1119, 2017.

MANOSSO, F. C.; GOMES, M. F.; AOKI, A.; MANOSSO, D. C. C. Distribuição Espacial e Temporal da Precipitação e Temperatura Média na Região da Serra do Cadeado (PR). Revista Brasileira de Climatologia. v. 12, n. 9, 2013.

MARENGo, J. A.; ALVES, L. M. Crise hídrica em São Paulo em 2014: seca e desmatamento. Geousp - Espaço e Tempo (Online), v. 19, n. 3, p. 485-494, 2016.

MCKEE, T. B.; DOESKEN, N. J.; KLEIST, J. The relationship of drought frequency and duration to the time scales. In: CONFERENCE ON APPLIED CLIMATOLOGY, Anhaeim, CA. Proceedings. Boston: American Meteorological Soceity, v. 8, p. 179-184, 1993.

MELO, M.C. Segurança hídrica para abastecimento urbano: proposta de modelo analítico e aplicação na bacia do rio das Velhas, Minas Gerais. Universidade Federal do Rio de Janeiro. 2016. 
MEZA, I.; HAGENLOCHER, M.; NAUMANN, G.; VOGT, J.; FRISCHEN, J. Drought

vulnerability indicators for global-scale drought risk assessments. Publications Office of the European Union, Luxembourg, 2019.

NASCIMENTO, M. B. DO; BANDEIRA, M. M.; ARAÚJO, L. E. DE. Variabilidade climática da precipitação do município de Areia/Paraíba, Brasil. Gaia Scientia, v. 13, n. 3, p.24-37, 2019.

NASCIMENTO, M. B.; ALMEIDA, N. V.; ARAUJO, L. E. Análise da variabilidade da precipitação pluviométrica na microrregião de Umbuzeiro, Paraíba. Revista Brasileira de Climatologia, v. 26, p. 233-248, 2020.

NÓBREGA, R.S.; SANTIAGO, G.A.C.F. Tendência de temperatura na superfície domar nos oceanos atlântico e pacífico e variabilidade de precipitação em Pernambuco. Mercator, v. 13, n. 1, p. 107-118, 2014.

NÓBREGA, R. S.; SANTIAGO, G. A. C. F.; SOARES, D. B. Tendências do controle climático Oceânico sob a variabilidade temporal da precipitação no Nordeste do Brasil Revista Brasileira de Climatologia, v. 18, p. 276-292, 2016.

NIKOLOVA, N. Regional Climatechange: Precipitation variability in mountainouspart of Bulgaria. Instituto Geográfico "jovancvijic" SASA. Coleção de Papeis, p. 79-86, 2007.

PALHARINI, R.S.A. \& VILA, A.D. 2017. Climatological Behavior Precipitating Clouds in the Northeast Regions of Brazil. Advances in Meteorology, p. 1-12.

PALMER, W. C. Meteorological drought. Washington: 1965. 65 p.

RODRIGUES, G. A.; CARLETO, N.; SANTOS, G. O. GERAÇÃO UM DE MAPA HIPSOMÉTRICO DA BACIA HIDROGRÁFICA DE TAQUARITINGA/SP. Revista Interface Tecnológica, v. 17, n. 1, p. 492-504, 2020.

ROSA, F.; DIAZ-BECERRA, O.; LUNKES, R. Basic Sanitation: Analysis of the Relationship between Public Expenditure and Services to the Population in Brazilian and Peruvian Cities. v. 14, n. 18, p. 195-213, 2016.

ROOY, M. P. V. A Rainfallanomaly index independentof time andspace, Notos. v. 14, p. 43-48, 1965.

SALES, D.C., COSTA, A.A., SILVA, E.M., VASCONCELOS JÚNIOR, F.C., CAVALCANTE, A.M.B., MEDEIROS, S.S., MARIN, A.M.P., GUIMARÃES, S.O., ARAUJO JUNIOR, L.M., PEREIRA, J.M.R. Projeções de mudanças na precipitação e temperatura no Nordeste Brasileiro utilizando a técnica de downscaling dinâmico. Revista Brasileira de Meteorologia v. 30, p. 435-456, 2015.

SANTOS, E. F. N.; SOUSA, I. F. ANÁLISE ESTATÍSTICA MULTIVARIADA DA PRECIPITAÇÃO DO ESTADO DE SERGIPE ATRAVÉS DOS FATORES E AGRUPAMENTOS. Revista Brasileira de Climatologia, v. 23, p. 205-222, 2018.

SANTIAGO, F. DOS S.; FREITAS, R. R. L. ; GOMES-SILVA, N. C.; BLACKBURN, R. M. Variabilidade de precipitação em assentamentos no Ceará. In: Anais... $7^{\circ}$ ENCONTRO INTERNACIONAL DAS ÁGUAS, Recife-PE, 2013, p. 1-7. 
SILVA FILHO, J. A.; FARIAS, C. A. S.; ARAúJO, S. C. Análise temporal do comportamento da precipitação pluviométrica no município de Pombal - PB. In: Anais... $2^{\circ}$ WORKSHOP INTERNACIONAL SOBRE ÁGUA NO SEMIÁRIDO BRASILEIRO, Campina Grande-PB, 2015, p. 1-6.

SOARES, F. B.; PIROLI, E. L. Análise da hipsometria e da declividade da bacia hidrográfica do rio pardo (São Paulo, Brasil) como subsídio para o planejamento ambiental da área. In: Anais... XVIII SIMPOSIO BRASILEIRO DE GEOGRAFIA FISICA APLICADA, SBGFA, Fortaleza-CE, 2019, p. 1-13.

SOUSA, A. M. L.; ROCHA, E. J. P.; VITORINO, M. I.; SOUZA, P. J. O. P.; BOTELHO, M. N. Variabilidade espaco-temporal da precipitação na Amazônia durante eventos ENOS. Revista Brasileira de Geografia Física, v. 8, n. 1, p.13-24, 2015.

SOUZA, S. A.; AMORIM, R. S.; REIS, D. S. Influência da correlação temporal e da multiplicidade de testes na detecção de tendências de índices de chuva no território brasileiro. Revista Brasileira de Climatologia, v. 26, p. 107-129, 2020.

TAVARES, C. M. G.; FERREIRA, C. C. M. A relação entre a orografia e os eventos extremos de precipitação para o município de Petropolis- RJ. Revista Brasileira de Climatologia, v. 26, p. 752-783, 2020.

UNCCD. United Nations Convention to Combat Desertification. Desertification: the invisible frontline. 2. ed. França: UNCCD, 2014.

UVO, C. R. B. A zona de convergência intertropical (ZCIT) e sua relação com a precipitação na região Norte e Nordeste brasileiro. São José dos Campos: USP. p. 99,1989.

VERNER, D. Vozes do povo: impactos socioeconómicos da seca no Nordeste do Brasil. In: DE NYS, E.; ENGLE, N.L.; MAGALHÃES, A.R. (orgs.). Secas no Brasil: política e gestão proativas. Brasília, DF: Centro de Gestão e Estudos Estratégicos- CGEE; Banco Mundial, 2016. 292 p.

WILHITE, D.A. Drought. In: HOLTON, J.A.; PYLE, C.; CURRY, J.A. (Ed.). Encyclopedia of atmospheric science. Elsevier, p. 650-658. 2003 